
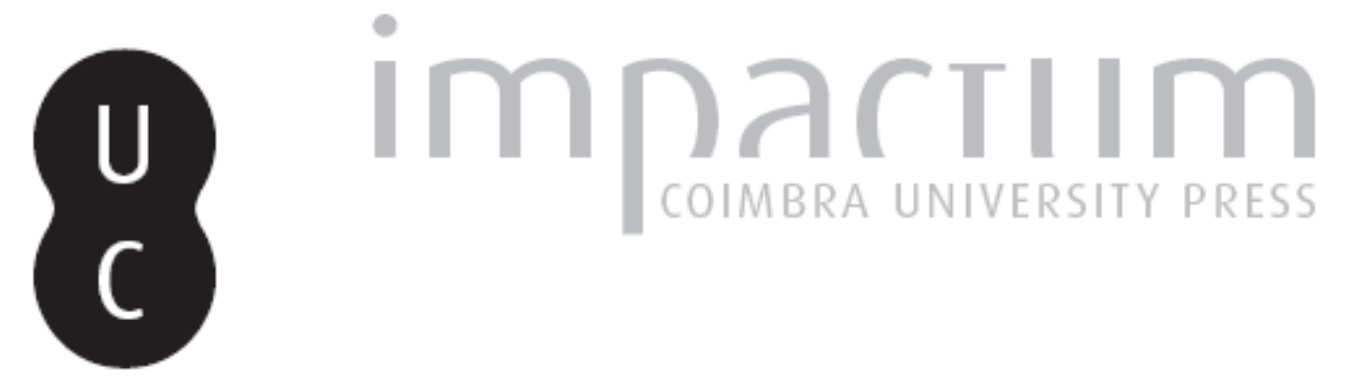

\title{
Por um serviço público de conteúdos
}

\section{Autor(es): $\quad$ Torres, Eduardo Cintra}

Publicado por: Imprensa da Universidade de Coimbra

URL persistente:

URI:http://hdl.handle.net/10316.2/39186

DOI:

DOI:http//dx.doi.org/10.14195/2183-6019_2_3

Accessed : $\quad$ 26-Apr-2023 08:18:14

A navegação consulta e descarregamento dos títulos inseridos nas Bibliotecas Digitais UC Digitalis, UC Pombalina e UC Impactum, pressupõem a aceitação plena e sem reservas dos Termos e Condições de Uso destas Bibliotecas Digitais, disponíveis em https://digitalis.uc.pt/pt-pt/termos.

Conforme exposto nos referidos Termos e Condições de Uso, o descarregamento de títulos de acesso restrito requer uma licença válida de autorização devendo o utilizador aceder ao(s) documento(s) a partir de um endereço de IP da instituição detentora da supramencionada licença.

Ao utilizador é apenas permitido o descarregamento para uso pessoal, pelo que o emprego do(s) título(s) descarregado(s) para outro fim, designadamente comercial, carece de autorização do respetivo autor ou editor da obra.

Na medida em que todas as obras da UC Digitalis se encontram protegidas pelo Código do Direito de Autor e Direitos Conexos e demais legislação aplicável, toda a cópia, parcial ou total, deste documento, nos casos em que é legalmente admitida, deverá conter ou fazer-se acompanhar por este aviso.

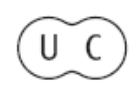


revista de comunicação,

jornalismo e espaço público

2

Periodicidade

Semestral

Imprensa da Universidade de Coimbra Coimbra University Press

\section{mediapolis}

tema

os desafios dos media

de serviço público

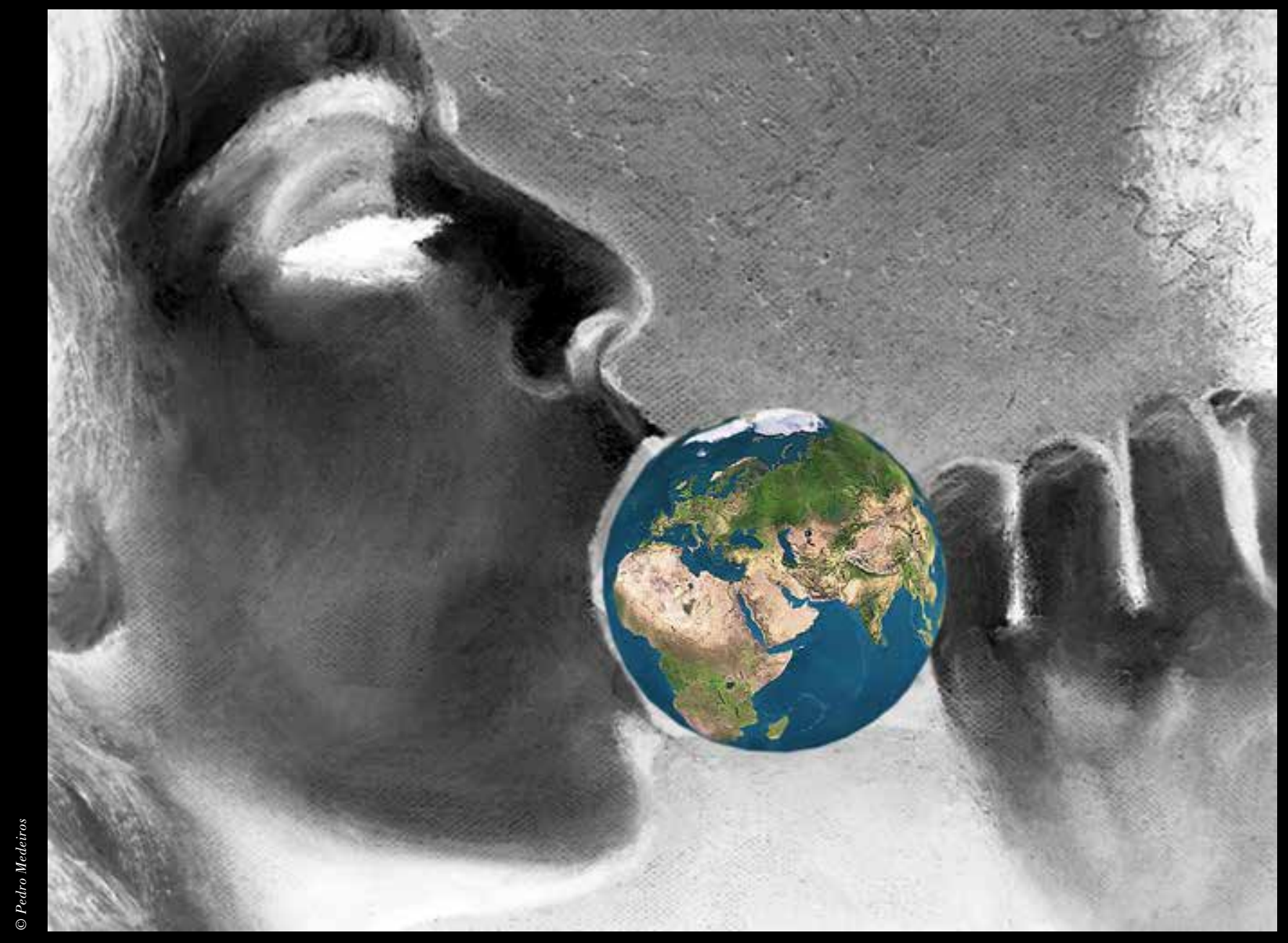




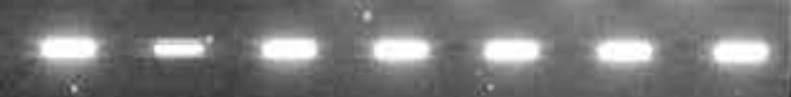

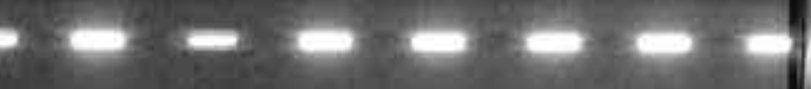

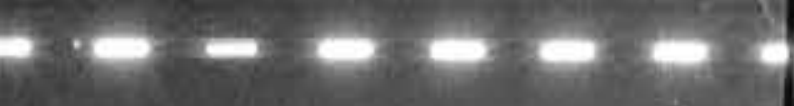

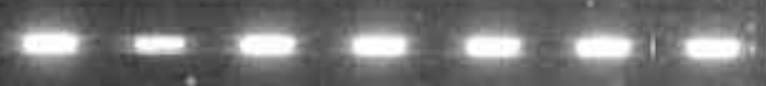
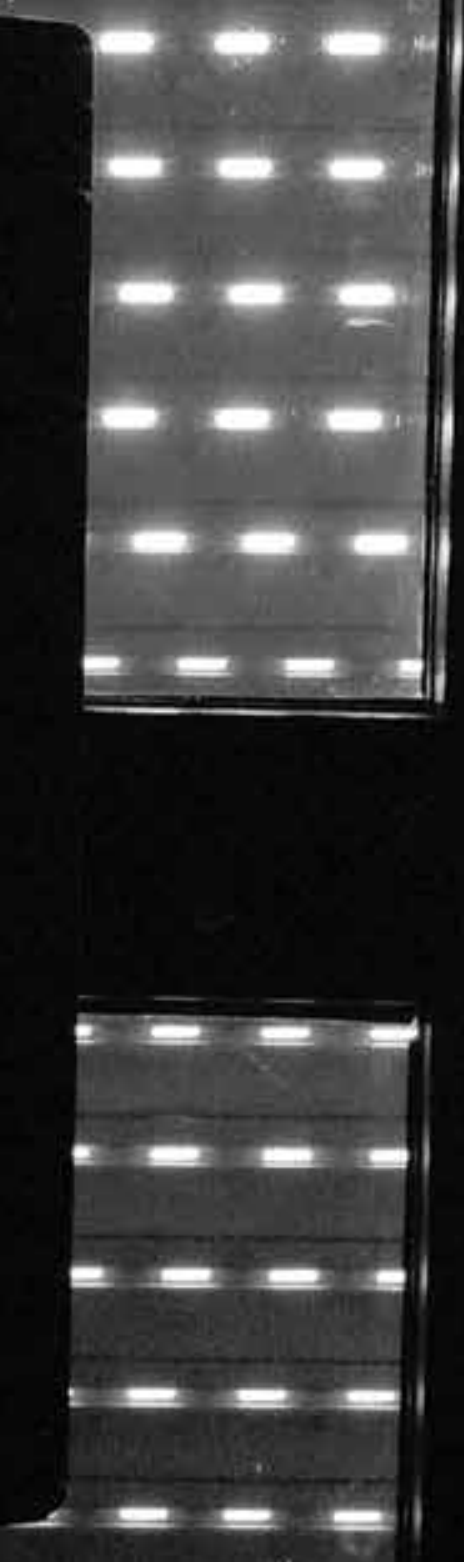

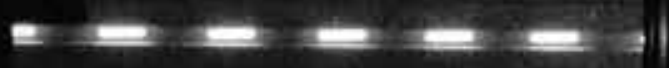

ex $-20+4$

$\underline{a n}-20$

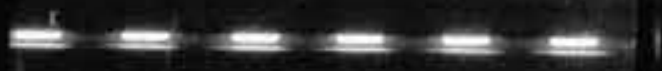

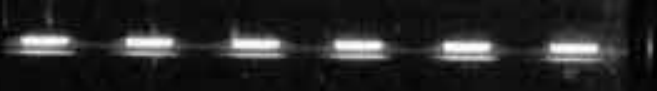

$=-0=0$

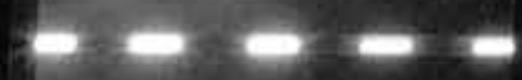

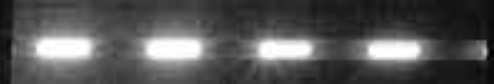

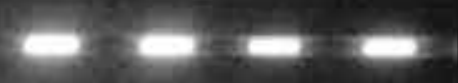

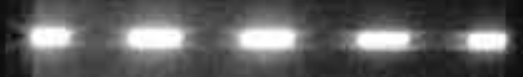

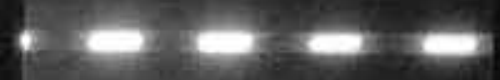

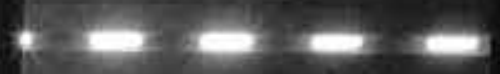

$2+x+20$

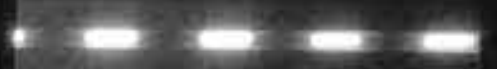

$\sec 2000$

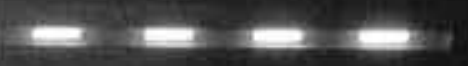

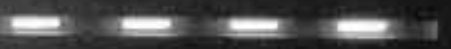

$x-\infty=0$

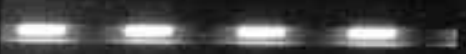

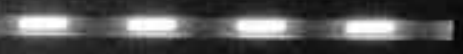

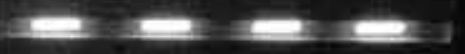

다이요

encese

$\mathrm{Ex}=0$

$=000$

encese

$=000$

$=0=0$

$=-0=$ bet 20

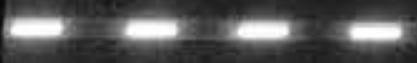

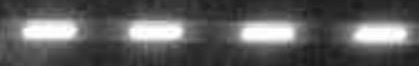

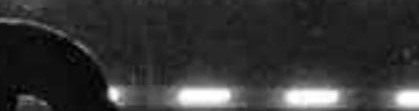

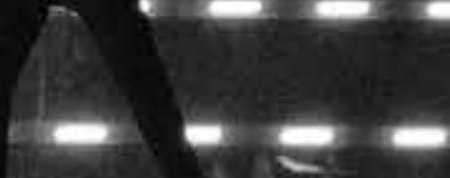

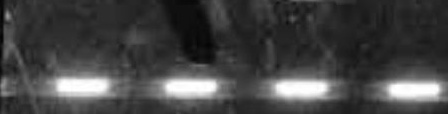

(4)

e $9=0$

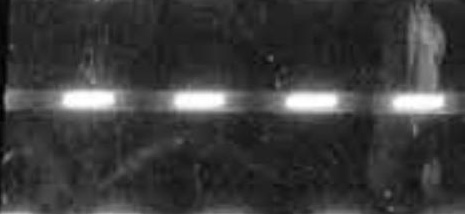

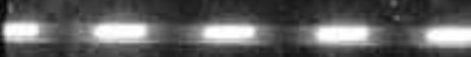

$2 x-20$ ren 20

$20+20$

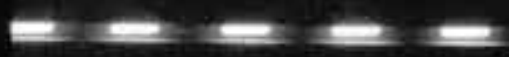

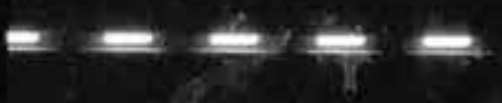

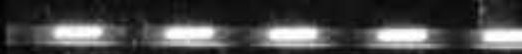

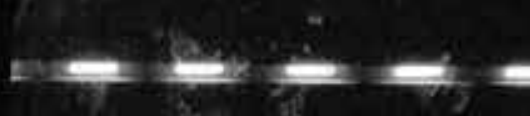

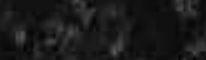

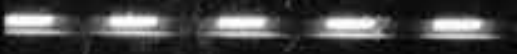

exint $5 \leq 0$

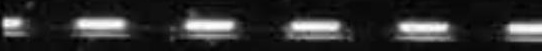

E $= \pm \equiv$ 


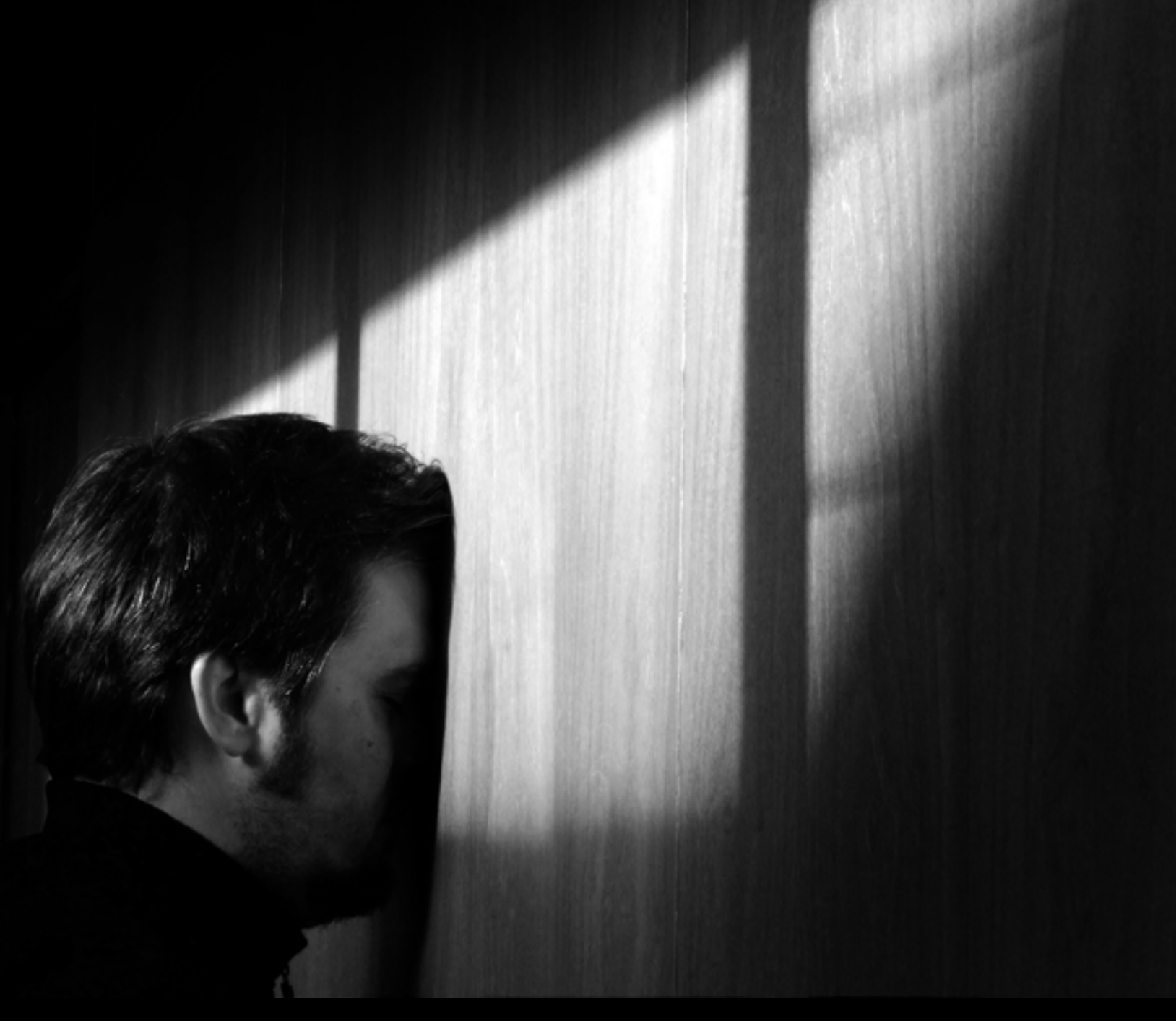




\title{
Por um serviço público de conteúdos
}

\author{
For a content public service
}

\section{Resumo}

Um debate sobre o "serviço público de media" deve centrar-se no passado recente e o presente dos media públicos e não no actual modelo institucional, tomado como eterno. Nesta intervenção, considero que a televisão se tornou, em primeiro lugar, para os espectadores mas também para outros intervenientes da sua existência, conteúdos próprios criados numa linguagem própria, com uma crescente independência face ao carácter institucional a montante e um crescente poder do espectador empoderado do século XXI. Em consequência, o debate deve partir dos conteúdos: que conteúdos deve um operador de serviço público estatal disponibilizar? Proponho que, em vez de "serviço público de media", se debata um Serviço Público de Conteúdos.

Palavras-chave: televisão, serviço público, conteúdos

\section{Abstract}

A debate about the "media public service" should concentrate in the recent past and the present of the public, State owned media and not in its present institutional model, taken for granted. In my communication, I consider that television became, for viewers and also for other players, primarily the contents, its own contents created in its own language, with a growing independence vis-a-vis its upstream institutional character and a growing power of the empowered viewer of the 21 st century. Consequently, the debate should begin with contents: what contents should a State public service institution make available? I propose that, instead of a "media public service", we should debate a Public Service of Contents.

Keywords: television, public service, contents
10 autor rejeita as alterações à ortografia constantes no chamado "Acordo Ortográfico" 
1.

Por facilidade, e por ser a minha área de investigação, concentrar-me-ei na televisão e não no conjunto dos media de serviço público, muito embora pense que grande parte do que afirmo se aplica também à rádio. A agência noticiosa é um caso diferente, por não ter concorrência nacional no serviço prestado e por estar limitada à produção noticiosa, duas características essenciais que não acontecem com a televisão e a rádio.

Desde há alguns anos começou a inquietar-me, em termos conceptuais, a insistência de debates sobre o futuro da televisão. Digo sobre o futuro da televisão e não sobre o passado recente e o sobre o presente. É inquietante porque o futuro da televisão é um lugar muito mais distante e desconhecido do que o presente e o passado.

Julgo que a discussão contínua e ciclicamente revisitada sobre o futuro da televisão e da RTP é uma forma de se evitar discutir o que interessa: o presente da televisão e da RTP. Pergunto-me se as inúmeras iniciativas sobre o futuro da RTP alguma vez contribuíram para melhorar o presente da RTP; ou pergunto-me mesmo o que foi o futuro da RTP quando essas iniciativas se realizaram? A resposta é: o futuro da RTP e do serviço público nunca, ou quase nunca, foi o previsto.

Partilho o que escreve Manuel Castells num dos seus mais recentes livros sobre comunicação: "I should make the reader aware of the fact that I never predict anything because I am distrustful of the methodologies generally used to predict the future by extrapolating the present [...]. Indeed, my preference is to play it safe and predict the past" (Castells, 2013:7).

2.

Revisitemos, pois, o passado recente e o presente, através de alguns elementos e dados rápidos e a toque de caixa ${ }^{1}$.

A audiência da TV generalista desce em todo os países desenvolvidos. O modelo de televisão de fluxo já não se coaduna, ou coaduna-se menos, com

1 Uma bibliografia sobre a "morte" da televisão e o seu presente está disponível no meu artigo "Por uma Definição Contemporânea de Televisão", Revista Ler, Lisboa, Dezembro de 2014, disponível em https://www.academia. edu/10844086/Por_uma_Definição_Contemporânea_de_Televisão_Looking_for_a_ Contemporary_Definition_of_Television o modo de vida individual e social e com as gratificações dos indivíduos no consumo de media. Em Portugal, ainda aumenta o consumo dos canais de cabo, mas nos EUA — que são, em muitos sentidos, o futuro da Europa o cabo também tem perdido assinantes. A geração dos mais novos, incluindo em Portugal, já não tem a televisão como media de primeira escolha.

A audiência que mais aumenta é a de plataformas disponíveis pela Internet: Google, YouTube, Facebook, Hulu, Netflix, Amazon. Há conteúdos divulgados pelo YouTube que obtêm em poucas horas mais visualizações do que aquelas que a maioria dos programas transmitidos por canais de televisão alguma vez terão. Em 2013, a Amazon produziu pela primeira vez uma série de televisão para vender aos seus clientes em todo mundo. $\mathrm{O}$ canal premium $\mathrm{HBO}$ já não está só no segmento chamado "TV de qualidade": a plataforma na Internet Netflix produziu a série premiada House of Cards. Os media não televisivos obtiveram dezenas de nomeações para os Emmy de televisão. Os media tradicionais de TV, as networks, só estiveram em maioria nas categorias de prémios de talk shows, reality shows e semelhantes. 
Há duas fragmentações de audiência em acção: a fragmentação colectiva do consumo de cada media e a fragmentação individual do consumo de cada media. Mesmo o consumo de notícias é crescentemente fragmentado. Uma significativa percentagem de consumidores de media contacta com notícias através de redes sociais e não através dos media tradicionais.

Aumenta significativamente o consumo de produtos mediáticos em aparelhos móveis. Nos EUA, o consumo de “vídeo móvel” foi o único a crescer nos últimos cinco anos, e não foi pouco: passou de $4 \%$ para $20 \%$, cinco vezes mais.

O consumo através do "televisor da sala" já é comandado por aparelhos externos. Não se liga o "televisor da sala" para ver canais, mas para ver conteúdos concretos, transmitidos ou não por esses canais.

Nos EUA o cabo também desce porque ele se inscreve no modelo tradicional de televisão. Ora, os consumidores querem conteúdos concretos e não canais. Esse terá sido sempre o modelo de recepção, mas actualmente a fragmentação e a tecnologia permitem-no com uma liberdade nunca antes conhecida. Por isso, cresce o consumo de conteúdos através do vídeo móvel, beneficiando de wifi gratuita em inúmeros locais, como cafés (Starbucks), universidades e, nos EUA, em 57 cidades.

No que toca à televisão, o zapping é em boa medida substituído pelo poder do indivíduo em optar pelo conteúdo que quer, qualquer que seja a sua origem, e consumido em diferentes tipos de equipamentos. Do zapping "horizontal", entre canais, passa-se ao zapping "vertical" entre conteúdos media, com menor ou mesmo sem o constrangimento temporal da sua disponibilidade.

Em consequência, diminui o contacto directo com canais. A primazia do consumo transferiu-se para conteúdos concretos.

Se a televisão se mantém o medium com maior impacto e em crescimento em várias partes do mundo, nos países mais desenvolvidos vai-se apagando essa preferência.

\section{3.}

Perante tantos desenvolvimentos, e a uma velocidade vertiginosa, no mundo da comunicação mediática, o que é a televisão hoje? Como defini-la? Essa foi uma questão, que me parece fulcral, a que tentei responder em $A$ Televisão e o Serviço Público ${ }^{2}$. Sem dúvida que subsiste uma importante, para não dizer essencial, dimensão institucional: empresas, governos e parlamentos decidem, fazem ou interferem com a criação de conteúdos, existem sistemas, plataformas e canais, etc.. Mas, apesar da crescente importância de novos agentes na actividade ou no negócio televisivo, como as grandes empresas globais (Google, Microsoft, Apple, Samsung, Sony, Netflix, Amazon, etc.), há uma maior ou mesmo nova liberdade dos indivíduos, de associações, de comunidades e também de empresas na escolha de conteúdos, na interacção e também na criação de conteúdos. Além disso, os desenvolvimentos técnicos libertaram os conteúdos, o acesso a conteúdos e a criação de conteúdos de quase todos os constrangimentos anteriores.

Todavia, ao contrário do que escreveram tantos que gostam de prever o futuro, a televisão não morreu. $\mathrm{O}$ que entrou em decadência foi a televisão generalista e o enquadramento institucional, não só da generalista, mas do que costumávamos chamar televisão. A institucionalidade também se fragmentou,

2 Lisboa, FFMS, 2011. 
tornou-se mais difusa, e, assim, diminui o seu poder sobre as audiências.

A televisão já não é o que era, mas está viva e recomenda-se. Julgo que o conceito de televisão, a definição de televisão em que a maioria, incluindo estudiosos, baseia as suas reflexões, já não serve. E, partindo-se de um conceito errado do que é a televisão hoje, corre-se o risco de propor futuros errados. Para um número crescente de espectadores, criadores, produtores e difusores, a televisão já não são canais e sistemas. Por isso, na minha definição, hoje a televisão são conteúdos feitos numa linguagem própria que o medium desenvolve ao longo de décadas, mantendo-se uma dimensão institucional de controle e produção, mas acrescentando-se o poder de escolha e, portanto, de decisão do indivíduo empoderado do século XXI. A televisão são conteúdos que reconhecemos como televisão, quer os contactemos num televisor, num SmartTV, num telemóvel, numa tablete, num computador, ou em qualquer outro ecrã. São conteúdos que encontramos em canais, mas também em redes sociais, em sites de empresas, de indivíduos, de jornais, em blogues, o que se quiser. E o que define um conteúdo como televisão é a sua linguagem, não a sua origem institucional. A série que a Amazon, em 2013, produziu e vendeu directamente aos clientes individuais, Alpha House, não passou por nenhuma instituição tradicional de televisão, mas é uma série de televisão porque usa a linguagem e um género de televisão num conteúdo que associamos à televisão.

Deste modo, basear a televisão do futuro em agentes institucionais e em canais é prever erradamente. Será melhor prever o passado para acertar no presente.

Qualquer passo em direcção ao futuro deve, a meu ver, partir dos conteúdos para o resto e partir dos conteúdos para o enquadramento institucional. Que conteúdos deve um serviço público estatal (SPE) proporcionar? ${ }^{3}$ Essa é, para mim, a única pergunta importante, e fulcral. Só depois de se saber que conteúdos deve o SPE proporcionar se deve estabelecer como proporcioná-los. Para isso, é preciso prever o passado, verificar como estão as gerações do futuro a consumir conteúdos. Não faz para mim qualquer sentido avançar com mais canais quando

3 Uso a expressão "um serviço público estatal", pois indicá-lo, como habitualmente se pratica, apenas como "o serviço público" é um erro propositado para inculcar uma ideologia nos receptores. sabemos que as pessoas não vêem canais, vêem conteúdos e, naturalmente, quando sabemos quais os conteúdos que o actual operador de SPE, a RTP, está a apresentar actualmente, hoje, a esta hora, logo à tarde, logo à noite. São estes os conteúdos que queremos? Vale a pena pagarmos por estes conteúdos?

A questão do preço a pagar não é de menos importância, pois todo o dinheiro público deve ser bem aplicado, criteriosamente. Não vou discutir orçamentos. Mas chamo a atenção para a desproporção entre o que o actual operador de SPE gasta em conteúdos e o que gasta em estrutura, etc. Julgo que nos últimos anos, o operador de SPE, a RTP, gasta em conteúdos, apenas, entre 1/4 e 1/5 do seu orçamento total. A meu ver, e dado que dou total primazia aos conteúdos de interesse público, julgo que o operador de SPE deveria ser reformado de forma a inverter esta relação, passando a gastar entre 3/4 e 4/5 em conteúdos e apenas o restante em estrutura, etc.

Naturalmente, a questão essencial regressa, qualquer que seja o orçamento disponível: que conteúdos deve o SPE proporcionar? Julgo que não é difícil um consenso alargado sobre ideias gerais, baseadas nos princípios consagrados do 
que deve ser um SPE. Difícil é passar das ideias gerais para o concreto.

Parece-me correcto usar a concepção que parte pela negativa: um SPE deve proporcionar conteúdos de interesse público alternativos aos que os privados podem ou querem oferecer; ou: um SPE deve proporcionar conteúdos que os privados não podem ou não querem proporcionar. Naturalmente, devem ser conteúdos de interesse público. Se não tiverem interesse público, porquê financiá-los com dinheiro público? E, desse modo, os conteúdos proporcionados no passado e no presente pelo actual operador de SPE, não no futuro, devem ser escrutinados segundo o seu interesse público. E esse escrutínio não pode limitar-se a conceitos gerais, como são os de género. É muito fácil dizer que o operador de SPE faz serviço público usando a classificação em géneros, mas, se isso bastasse, também os generalistas privados o fariam: avaliando os géneros exibidos pela RTP1, SIC e TVI em Outubro de 2013, verifiquei que não há qualquer diferença significativa entre os três canais, pelo contrário. Além disso, a classificação de géneros pode ser forçada para agradar à classe política, a quem está cometida o escrutínio do serviço prestado pelo operador de SPE. Dois exemplos: o programa Príncipes do Nada foi classificado pela RTP como documentário, o que ofende qualquer estudioso ou apreciador do género no cinema ou na televisão; e telenovelas apresentadas na RTP1 são classificadas como séries, para desvirtuar as estatísticas. Deste modo, a verificação do interesse público não pode ser realizada por análise genérica ou análise de conteúdo, mas caso a caso, com um mínimo de análise textual. Se for avante a proposta de novo Contrato de Concessão do Estado com o actual SPE, espero que o escrutínio não só seja mais acutilante como verdadeiro, sendo inescapável que se concretize através da análise textual de cada programa ou segmento.

4.

$\mathrm{O}$ actual governo já teve diferentes estratégias em relação ao SPE. Aconteceu o mesmo com governos anteriores. As estratégias esbarram sempre na questão institucional: a RTP. A meu ver, a questão institucional RTP sobrepõe-se a qualquer debate razoável, para não dizer racional, sobre o tema do serviço público.

Desta forma, os debates ficam enviesados à partida, pois não se parte do interesse público para o modo institucional adequado, mas do modo institucional para o que a instituição deve fazer. Para mim, o essencial do serviço público de media são conteúdos de interesse público, que melhorem a qualidade da cidadania. $\mathrm{O}$ essencial é proporcionar conteúdos de interesse público aos cidadãos, onde quer que estejam e como quiserem consumi-los. O que precisamos é de pensar o serviço público, não como "serviço público de media", mas como Serviço Público de Conteúdos, conteúdos concretos, que é aquilo que os cidadãos de hoje e os cidadãos de amanhã vêem nos ecrãs. Para isso, precisamos de prever o passado recente, prever o presente e não embarcar no canto da sereia sobre o "futuro", que serve em primeiro lugar para ocultar o que se fez e o que se vem fazendo.

\section{Bibliografia}

Castells, M. (2013). Digital networks and the Culture of the autonomy. In Ma Castells, Communication Power Prediction the recent past. Oxford and New York: Oxfornd University Press. 